\title{
Review Article on Covid-19
}

\author{
Amlan Mohanty, Mukund Ganeriwal and Nandkishor Bankar \\ ${ }^{1}$ First Year MBBS, Datta Meghe Medical College, Nagpur, India \\ ${ }^{2}$ Department of Medicine Datta Meghe Medical College, Nagpur, India \\ ${ }^{3}$ Department of Microbiology Jawaharlal Nehru Medical College, Datta Meghe \\ Institute of Medical Sciences Sawangi (Meghe), Wardha, India \\ Corresponding author email: drbankarnj28@gmail.com
}

\section{ABSTRACT}

The World Health Organization called a new coronavirus (CoV) named coronavirus 2019 (COVID-19) after it was discovered in a seafood market in Hubei province in Wuhan, China, in late 2019. (WHO). COVID-19 is highly susceptible to coronavirus-2 (SARS-CoV2), posing major public health risks as well as global economic threats. Unfortunately, the cause of the COVID-19 virus is unknown, and there is no successful treatment for this virus that has recently endangered human life and property. As a result, it's critical to look for other ways to slow or stop the spread of COVID-19. We try to figure out the etiology, epidemiology, symptoms, and transmission of this novel virus in this study. We also review medical treatments and recommend antiviral medications, antibodies, regular supplements, and direct CoV care to prevent SARS-CoV and Middle East respiratory coronavirus recurrence and reproduction (MERS-CoV). Life is so precious we have to look after our precious life. We will definitely obey the norms what has been prescribed by the government like social distancing, sanitization, hand washing, wearing mask, etc. to confront the pandemic COVID-19.

KEY WORDS: COVID-19, SARS-COV-2, MERS-COV, WHO AND SYMPTOMS.

\section{INTRODUCTION}

COVID-19 commonly known to the World a china virus broke out in 2019, ushering deadly dance of death disease, devastation, desolation and doom threatening to the sustainability of the mankind it has been proved that when nature red in tooth and claw no one can dare to challenge it however developing and developed a nation you are. To a medical expert COVID-19 is a pandemic to a mythologist it is an approach to a micro biologist corona virus is an unseen invisible infectant and above all a biological weapons like plague, anthrax, ricin botulism and variola COVID-19 or SARS Cov-2 has speared throughout the world affecting more than 200 countries

Biosc Biotech Res Comm P-ISSN: 0974-6455 E-ISSN: 2321-4007

\section{rossef}

Identifiers and Pagination

Year: 2021 Vol: 14 No (7) Special Issue

Pages: 33-36

This is an open access article under Creative

Commons License Attribn 4.0 Intl (CC-BY). DOI: $h t t p: / / d x$.doi.org/10.21786/bbrc/14.7.8 breaking down the world economy with this discouraging morbidity and mortality figures. It has stared in one China with symptoms of pneumonia. Researchers identify two virus of the one sea food market of chiropetra origin as indicated by their scientific name (bats) bat-SL COVZC45 and bat SL COVZXC21 (Lei J et al., 2018).

\section{Symptoms of Disease:- \\ Symptoms are three types: \\ 1. Most Common symptoms \\ - Fever \\ - Dry Cough \\ - Tiredness}

\section{Less common symptoms}

- Aches and pains

- Diarrhea

- Conjunctivitis

- Headache

- Loss of taste or smell

- A rush on skin or discoloration of fingers or toes
Article Information

Received: $18^{\text {th }}$ April 2021 ccepted after revision: $06^{\text {th }}$ June 2021 


\section{Serious Symptoms.}

- Difficulty breathing or shortness of breath

- Chest pain or pressure

- Loss of speech or movement.

When one will be affected by the virus of COVID-19, the symptoms will appear within 14 days. Fever: The disease of fever is very common to us. When body temperature rises from 986 degree it is called as fever. When one will be suffer he will test his blood. From testing of blood one will sure about the reason of fever such as malaria, cold, dengue and other infections, there is medicine. But it is unfortunate that there is no any medicine has been invented for the disease like COVID19. From the instances of Brazil we came to know that if peoples will be affected by the dengue there is ever possibility to attach by the COVID. Hypothalamus is an important part in our brain. It gives signal whether our body infected by any virus or not. If body is infected by virus hypothalamus indicates that to increase body temperature.(Silverman MN et al.,2005)

Dry Cough: Dry cough is complete symptom for a patient, complete cough is not gone away by coughing. Dry cough is cured by taking medicines if it is on the ground of cold and fever ground. But if it is through COVID-19 ground than it is another thing. If one will suffer from dry cough the lungs will be badly affected. Respiratory parts of our body will be harmed by which mucus phlegm can be produced. In dry cough scratchy or rough throat will be happened. Dry cough is associated with so many other symptoms like shortness of breath or difficulties on breathing, Diarrhea, Muscles or joint pain. This dry cough will give many difficult pain to the patient. The lungs will be affected by the dry cough. One can die also due to this dry cough.3 After the recovery from the COVID-19 the harmful cough may continue for long time.

Tiredness: This is the most common symptoms of COVID19. Tiredness is otherwise called fatigue. When one will be in fatigue he will not get energy to walk, to lift upstairs etc. but people knew first time that tiredness is one of the important symptoms of COVID-19. A normal person when suffer from weakness goes to doctor. He thinks that he has shortage of vitamin in his body. But this concept turned wrong. Body is immune system detoriorates and he falls in to tiredness. We cannot breath properly when we should not drink water when we are tired as drinking water at that time can make pressure to the body part especially breath and if cold is there in the body drinking water may cause more damage.

One can become tired by coughing more cough is also a symptom of COVID-19: General tiredness of and COVID19 tiredness is a peculiar type of tiredness when person fall in high sleep also. Patient feel totally discomfort in this stage. Memory will loss. This is an extreme symbol of COVID-19. Patient will unable to recognize persons and things also. This is otherwise called as 'brain fog'. This tiredness symptoms is less in case of children and young adults. In first wave of corona fatigue sign has not much depicted as compared to 2nd wave. In second wave the symptoms of tiredness is very prominent. The fatigues may continue after the recovery from the disease also. Many recovered patient and physicians have given their opinion (Substance Abuse 2016).

\section{Less common symptoms:-}

Aches \& Pains: The US center for disease control and prevention recently notified recently aches and muscle pain one of the prominent symptoms to COVID-19. WHO is also recognized to muscle pain as another symptom of COVID-19. WHO reported that CHINA Govt. tented to 55924 COVID affected people. Among them near about $14.8 \%$ peoples hand the sign of muscle pain. Muscle pain can causes muscle inflammation which is otherwise called as myositis also another symptoms of COVID-19. Due to corona virus the muscles fibers are also damaged roughly. Sometimes doctors fall in difficulty to diagnosis the cause of muscle pain. There are may be other cause of muscle pain. It may be due to imperial, heavy works or cold or another causes. In muscle pain due to COVID-19 one should take bed rest. Pain relievers like acetaminophen should be taken (Carbone M 2021).

Sore throats: Due to cold or infection if anybody fall pain in swelling or without swelling, then it is called sore throat. Generally in cold one feel about sore throat by taking antibiotics are the relive by taking antibiotic sore throat is less common symptoms of COVID-19. Different Scholars have studied that the symptoms arises in the body of 5-7\% of patient. This is the early symptoms of COVID-19. As we know COV-19 viruses first enter to nose or mouth than goes to throat etc. Obviously it is proved that throat infection or throat soar will definitely occurs. Immediate remedy from sore throat is to drink hot water, use warm shower gargling with salt water, take tea, coffee, etc (Johnson KD 2020).

Diarrhea: In early time diarrhea was recognized as the symptom to COVID-19. But subsequently WHO and other physician proved that diarrhea is also a symptom to COVID-19. Through the facial-oral route the virus goes to stool. The infection then spread the diseases. The data of gastrointestinal symptom tells that the symptom falls on the 5-10\% patient. The patient in sever condition will show the symptom of diarrhea. But he people in less symptom will not show the symptom in diarrhea they needs ventilation.

Conjunctivitis: This is a type of eye disease caused by infection. Outer membrane of the eye ball will be inflamed, eye will become pink color. The eye will red. Itching will continue and tearing will take place. One 
will be very irritated. SJ. Mohan Ranjan, Chairman and medical director of Ranjan Eye care Hospital opined that it must be the primitive symptoms of COVID-19. In second wage physician assured that conjunctivitis is the first symptom of COVID-19. Studies show that some patient may not have primary symptoms like fever, cough, tiredness, but they may have symptom of conjunctives.

Headache: Feeling in any part of the head basically in forehead is called head ache. Headache is called due to tiredness stress, strain without sleep, less sleep, tension due to wrong power of glasses etc. there are so many cause of head ache one of them is COVID-19. Different report shows that head ache may be earlier time of infection or it may be at the time of infection. Head ache as a symptom is depicted in the $11-34 \%$ of the people. Under the age group of 65 head ache is a common symptom.

Loss of Taste or smell: It is an important symptom which makes a people unhappy, helpless. COVOD-19 is such dangerous disease. In cold and sinus infection people also loss the taste and smell. Without a runny or stuffy nose a patient will suddenly lose his sense of taste due to COVID-19. Taste loss and smell less may the early symptoms like other symptoms such as fever and cough etc. first it occurs. Then other symptoms come out.

Loss of smell and taste is slightly longer than upper respiratory infections.

Serious Symptoms: Difficulty breathing or shortness breathing: Difficulty in breathing or shortness of breath is caused due to exercise, tightness etc. Air cannot inhalant fully due to illness of lungs and hearts.

Asthma, a chest infection, panic attack, heart diseases, anxiety, etc. the sole causes of shortness in breathing. When corona virus goes to heart and lungs then infected the lungs. Lung infection leads to pneumonia infection.

"Breathlessness" and "dyspnea" is a serious symptoms develop in one body where air cannot pass into the lungs. Airs remain in the throat. Person feels that as if he or she cannot breathing deeply. Natural breathing process will be disrupted.

Breathing problems are very serious problems. Patient fight for their lives. There are three types of breathing causes.

- Some people feel that they totally cannot breath.

- Other category feel that they are taking less portion of the oxygen.

- Third category people feel that full tightness in chest in inhalation and exhalation.
Some studies reflect that difficulty in breathing continues averagely 5 days. If corona virus affects the lung tissues it create damage speedily the epithelial cell lining the air ways. The inflation will be made in affected tissues of the immune system. Inflammatory immune response continues to inhibit the regular transfer of gasses including oxygen in the lungs and fluid can buildup. The combination of these factors create difficulty in breathing. In case of severe infection we have to admit in hospital. The conditions are:-

- Having pain in chest

- Feeling coughing in inhaling situation.

- Feeling uncomfortable for breathing.

If a person symptomizes the following, he / she will have to admit in ICU. The symptoms are:

- A patient will unconscious

- His/her lips, face, nails will be in pall or bluish colour.

- Chest pain will continue.

In these cases patient will admit in to the ventilator. By ventilator mechanism artificially oxygen is provided to the patient. Natural breathing is impossible in this case. In ICU different treatments are carried on besides ventilation. Because other organs linked with blood continues to waste a multi organ failure treatment are necessary to clear the patient. 12

Chest pain or pressure: Chest pain are different types some are unable or minor but in the case there may be dangerous to health. Chest pain may be caused due to heart attack, COVID or anxiety. Discomfort arises on the ground of squeezing, feeling sharp pain, burning sensation for chest pain. On the ground of COVID-19 muscle pain may be happened. There are muscles in chest and lungs so as every muscles will create pain. Chest muscle will sense the pain. Due to COVID pneumonia may attack. Due to pneumonia lungs and chest may be inflamed. This also creates chest pain. 14 Many related studies have been reported. Studies by Godhiwala et. al, Gupta et. al., Hande ett. al. 21 and Jachak et.al. 22 were reviewed.

\section{CONCLUSION}

Life is so precious we have to look after our precious life. We will definitely obey the norms what has been prescribed by the government like social distancing, sanitization, hand washing, wearing mask, etc. to confront the pandemic COVID-19.

\section{REFERENCES}

Angus-Leppan H, Guiloff AE, Benson K, Guiloff RJ. Navigating migraine care through the COVID-19 pandemic: an update [published online ahead of print, 
2021 May 17]. J Neurol. 2021;1-8. doi:10.1007/s00415021-10610-w

Carbone M, Lednicky J, Xiao SY, Venditti M, Bucci E. Coronavirus 2019 Infectious Disease Epidemic: Where We Are, What Can Be Done and Hope For. J Thorac Oncol. 2021;16(4):546-571. doi:10.1016/j. jtho.2020.12.014

COVID-19 rapid guideline: managing the long-term effects of COVID-19 (NG188): Evidence reviews 2 and 3: prevalence. London: National Institute for Health and Care Excellence (UK); 2020 Dec. (NICE Guideline, No. 188.) Available from: https://www.ncbi.nlm.nih.gov/ books/NBK567266/

D’Ascenzi F, Cameli M, Forni S, et al. Reduction of Emergency Calls and Hospitalizations for Cardiac Causes: Effects of Covid-19 Pandemic and Lockdown in Tuscany Region. Front Cardiovasc Med. 2021;8:625569. Published 2021 Mar 12. doi:10.3389/fcvm.2021.625569

Dhadse, P., V, Kiran Sethiya, Chitrika Subhadarsanee, and Khushboo Durge. "The Novel Corona Virus (NCoV2) Seems To Defy All Laws Of Virology.” International Journal of Pharmaceutical Sciences And Research 11, no. 9 (September 2020): 4104-13. https://doi. org/10.13040/IJPSR.0975-8232.11(9).4104-13.

Dholakia, Yatin, Zahiruddin Quazi Syed, and Nerges Mistry. "Drug-Resistant Tuberculosis: Study of Clinical Practices of Chest Physicians, Maharashtra, India." LUNG INDIA 29, no. 1 (March 2012): 30-34. https:// doi.org/10.4103/0970-2113.92359.

Godhiwala, Parth, Sourya Acharya, Gaurav Jagtap, Arvind Bhake, and Samarth Shukla. "Leukemoid Reaction in a COVID-19 Patient.” Journal Of Evolution Of Medical And Dental Sciences-JEMDS 10, no. 6 (February 8, 2021): 399-400. https://doi.org/10.14260/ jemds/2021/88.

Gupta, Kunal, Dimitrios Emmanouil, and Amit Sethi. "Use of Nitrous Oxide-Oxygen Inhalation Sedation in the COVID-19 Era." International Journal Of Paediatric Dentistry, n.d. https://doi.org/10.1111/ipd.12745.

Hande, Alka, Archana Sonone, Amol Gadbail, Madhuri Gawande, Swati Patil, and Preethi Sharma (March 2021). "Modalities to Restrain the Progression of Oral Potentially Malignant Diseases and Oral Squamous Cell Carcinoma in COVID-19 Pandemic." ORAL ONCOLOGY 114. https:// doi.org/10.1016/j.oraloncology.2020.105072.

Jachak, Shrushti Prashant, Pratik Arun Phansopkar, Waqar Mohsin Naqvi, and Kiran Kumar (November 9, 2020). "Great Awakening - Telerehabilitation in Physiotherapy during Pandemic and Impact of Covid19." Journal Of Evolution Of Medical And Dental Sciences-Jemds 9, no. 45: 3387-93. https://doi. org/10.14260/jemds/2020/744.

Jeong TH, Pak C, Ock M, Lee SH, Son JS, Jeon YJ (2020). Real Asymptomatic SARS-CoV-2 Infection Might Be Rare: Importance of Careful Interviews and Follow-up. J Korean Med Sci;35(37):e333. Published 2020 Sep 21. doi:10.3346/jkms.2020.35.e333

Johnson KD, Harris C, Cain JK, Hummer C, Goyal H, Perisetti A (2020). Pulmonary and Extra-Pulmonary Clinical Manifestations of COVID-19. Front Med (Lausanne);7:526. Published 2020 Aug 13. doi:10.3389/ fmed.2020.00526

Lei J, Kusov Y, Hilgenfeld R (2018 Jan). Nsp3 of coronaviruses: Structures and functions of a large multi-domain protein. Antiviral Res;149:58-74.

Lo Bianco G, Di Pietro S, Mazzuca E, et al (2020). Multidisciplinary Approach to the Diagnosis and In-Hospital Management of COVID-19 Infection: A Narrative Review. Front Pharmacol;11:572168. Published 2020 Dec 9. doi:10.3389/fphar.2020.572168 McGonagle D, Sharif K, O'Regan A, Bridgewood C (2020). The Role of Cytokines including Interleukin-6 in COVID-19 induced Pneumonia and Macrophage Activation Syndrome-Like Disease. Autoimmun Rev;19(6):102537. doi:10.1016/j.autrev.2020.102537.

Nouri-Vaskeh M, Sharifi A, Khalili N, Zand R, Sharifı A (2020). Dyspneic and non-dyspneic (silent) hypoxemia in COVID-19: Possible neurological mechanism. Clin Neurol Neurosurg;198:106217. doi:10.1016/j. clineuro.2020.106217

Shrivastava, Priyal, Mahalaqua Nazli Khatib, Shilpa Gaidhane, Dipti Shrivastava, Abhay M. Gaidhane, and Zahiruddin Quazi Syed ((February 2020)). Assessment of Mean Platelet Volume (MPV) in Subjects with Type 2 Diabetes Mellitus (T2DM) in a Rural Backdrop of Central India." MEDICAL SCIENCE 24, no. 101: 12-21.

Silverman MN, Pearce BD, Biron CA, Miller AH (2005). Immune modulation of the hypothalamic-pituitaryadrenal (HPA) axis during viral infection. Viral Immunol;18(1):41-78. doi:10.1089/vim.2005.18.41

Substance Abuse and Mental Health Services Administration (US); Office of the Surgeon General (US). Facing Addiction in America: The Surgeon General's Report on Alcohol, Drugs, and Health [Internet]. Washington (DC): US Department of Health and Human Services; 2016 Nov. Chapter 4, Early Intervention, Treatment, And Management of Substance Use Disorders. Available from: https://www.ncbi.nlm. nih.gov/books/NBK424859/

Sun CB, Wang YY, Liu GH, Liu Z (2020 Apr 24). Role of the Eye in Transmitting Human Coronavirus: What We Know and What We Do Not Know. Front Public Health. 2020;8:155. Published. doi:10.3389/fpubh.2020.00155 Vagga, Anjali Ambadas, and Archana Janardan Dhok (August 31, 2020). "Blessings in Disguise: Yoga and Meditation during Corona Lockdown." Journal of Evolution of Medical And Dental SciencesJemds 9, no. 35: 2540-44. https://doi.org/10.14260/ jemds/2020/552.

Xu Z, Shi L, Wang Y, et al (2020). Pathological findings of COVID-19 associated with acute respiratory distress syndrome [published correction appears in Lancet Respir Med. 2020 Feb 25;:]. Lancet Respir Med;8(4):420-422. doi:10.1016/S2213-2600(20)30076-X 